OPEN ACCESS

Edited by:

Karen Lynne Kline,

VCA Inc., United States

Reviewed by:

Winfried Mayr

Medical University of Vienna, Austria

Michel Lemay,

Temple University, United States

*Correspondence:

Ângela Martins

vetarrabida.lda@gmail.com

Specialty section

This article was submitted to

Veterinary Neurology and

Neurosurgery

a section of the journal

Frontiers in Veterinary Science

Received: 22 August 2020

Accepted: 03 June 2021

Published: 01 July 2021

Citation:

Martins Â, Gouveia D, Cardoso A,

Viegas I, Gamboa Ó and Ferreira A (2021) A Comparison Between Body

Weight-Supported Treadmill Training and Conventional Over-Ground Training in Dogs With Incomplete

Spinal Cord Injury.

Front. Vet. Sci. 8:597949

doi: 10.3389/fvets.2021.597949

\section{A Comparison Between Body Weight-Supported Treadmill Training and Conventional Over-Ground Training in Dogs With Incomplete Spinal Cord Injury}

\author{
Ângela Martins ${ }^{1,2,3 *}$, Débora Gouveia ${ }^{1}$, Ana Cardoso ${ }^{1}$, Inês Viegas ${ }^{1}$, Óscar Gamboa ${ }^{4}$ and \\ António Ferreira ${ }^{3,4}$ \\ ${ }^{1}$ Arrábida Veterinary Hospital-Animal Rehabilitation Center, Azeitão, Portugal, ${ }^{2}$ Faculty of Veterinary Medicine, Lusófona \\ University, Lisboa, Portugal, ${ }^{3}$ CIISA - Centro Interdisciplinar de Investigação em Saúde Animal-Faculty of Veterinary \\ Medicine, Lisboa, Portugal, ${ }^{4}$ Faculty of Veterinary Medicine, University of Lisbon, Lisboa, Portugal
}

In human medicine there was no evidence registered of a significant difference in recovery between body weight-supported treadmill training (BWSTT) and conventional over-ground (COGl). There isn't any similar study in veterinary medicine. Thus, this study aimed to compare the locomotor recovery obtained in incomplete SCl (T11-L3 Hansen type I) post-surgical dogs following BWSTT or COGI protocols, describing their evolution during 7 weeks in regard to OFS classifications. At admission, dogs were blindly randomized in two groups but all were subjected to the same protocol (underwater treadmill training) for the first 2 weeks. After, they were divided in the BWSTT group $(n=10)$ and the COGl group $(n=10)$ for the next 2 weeks, where they performed different training. In both groups locomotor training was accompanied by functional electrical stimulation (FES) protocols. Results reported statistically significant differences between all OFS evaluations time-points $(p<0.001)$ and between the two groups $(p$ $<0.001$ ). In particular with focus on T1 to T3 a two-way repeated measures ANOVA was performed and similar results were obtained $(p=0.007)$. Functional recovery was achieved in $90 \%$ (17/19) of all dogs and 100\% recovered bladder function. The BWSTT group showed $100 \%(10 / 10)$ recovery within a mean time of 4.6 weeks, while the COGI group had 78\% (7/9) within 6.1 weeks. Therefore, BWSTT leads to a faster recovery with a better outcome in general.

Keywords: dogs, rehabilitation, treadmill, over-ground training, spinal cord injury

\section{INTRODUCTION}

Intervertebral degenerative hernia (IVDH) is the most common cause of acute spinal cord injury (SCI) in dogs, with a prevalence as high as $19 \%$ in some breeds (1-3). The most prevalent type of IVDH is extrusion thoracolumbar IVDH Hansen type I (4). IVDH can occur in any breed of dogs (5), but it typically affects chondrodystrophic dogs at an age ranging from 3 to 6 years. However, it also occurs in non-chondrodystrophic dogs $(6,7)$. 
The clinical signs of IVDH vary, ranging from spinal hyperesthesia to hindlimb paralysis $(8,9)$. Severe clinical signs that imply the loss of voluntary motor function after acute SCI are mostly caused by contusion (7). IVDH Hansen type I results in mixed contusive and compressive injury (10-12) and causes both primary and secondary lesions (13). This condition can benefit from decompressive surgery (14), particularly in the case of dogs with rapidly deteriorating neurological status (15).

Moore et al. reported that $43 \%$ of veterinarians routinely recommend a postsurgical rehabilitation program, with the treatment beginning immediately after surgery. It has been reported that nursing care of these dogs benefits their recovery of ambulation. In addition, there are many diverse recommendations, ranging from no restriction to strict cage rest up to 8 weeks post-surgery (3).

In human medicine, rehabilitation strategies aim to improve stepping recovery after SCI (16). Locomotor training exercises with step repetitions for several minutes each day for several consecutive weeks improve muscle force output and endurance (17) and also promote functional plasticity in locomotor central pattern generators (CPGs) present in the spinal network (18).

Locomotor training based on repetitions also affects the characterization and quality of gait through more complex mechanisms, such as the stimulation of residual descending/ascending pathways. Thus, locomotor training facilitates the recovery of ambulation after incomplete SCI (17).

The spinal cord depends on sensory feedback to generate force during stepping. In cats with spinal injury, a direct access between the cutaneous inputs and spinal rhythm-generating circuitry is suggested and treadmill training can provide $50 \%$ of the force generated during the stance phase (19).

In humans, high-intensity locomotor training promotes the release of various trophic factors, such as brain-derived neurotrophic factor (BDNF), which may facilitate angiogenesis, neurogenesis, neuro-reorganization changes, and muscle metabolism $(20,21)$. This type of training in humans with SCI includes body weight-supported treadmill training (BWSTT), which plays an important role in posture and gait (22). In addition, BWSTT can increase the amplitude and coordination of firing of muscle motor units (23).

Dobkin et al., compared gait evolution by BWSTT and by conventional over-ground intervention (COGI) and found that there was no significant difference between the two treatments up to 3 months (24). Thus, BWSTT did not differ significantly from COGI in terms of kinematic and kinetic parameters (25-27). A study by Field-Fote and Roach indicated that gains in walking speed obtained with COGI were equivalent to gains achieved with BWSTT and that regarding walking distance, COGI was superior (28).

An association between functional electrostimulation (FES) and locomotor training that improves normality in speed, distance, and limb coordination has been reported (29). In addition, FES improves stride, length, cadence, and gait quality, as well as muscle strength and activation (29, 30). FES with locomotor training is implemented in individuals with complete or incomplete SCI (31). This electrostimulation modality, targets restorative neurology by modifying residuals and remaining nervous system circuits and pathways (32).

Given that rehabilitation protocols are already successfully used in humans, it is considered to be a therapy with reasonable translational potential for veterinary medicine (33). Thus, this study aimed to compare the application of the BWSTT protocol vs. the COGI protocol in dogs with incomplete sub-acute SCI (T11-L3 IVDH Hansen type I) after surgery.

\section{MATERIALS AND METHODS}

\section{Participants}

This was a controlled, blinded, prospective clinical study using a cohort criterion in dogs. Dogs presenting with an acute history of thoracolumbar SCI with IVDH Hansen type I after hemilaminectomy at one or two sites were included. The time between onset of disease and surgery was $\sim 2-4$ days, during which they were treated with a pharmacological approach with non-steroidal anti-inflammatories or with low doses of corticosteroids. All dogs were diagnosed using computerized tomography (CT) or magnetic resonance imaging (MRI) with T11-L3 neuro-localization.

All modified Frankel Scale (MFS) grade I dogs, regardless of sex and breed, were included in this study and were admitted to the rehabilitation center up to 7 days postoperatively. Other inclusion criteria were weight $\leq 20 \mathrm{~kg}$ and age from 2 to 8 years.

At admission, all participants underwent a neurorehabilitation functional examination and a standard upper motor neuron examination and showed decreased or absent withdrawal reflexes in one or both pelvic limbs. This status, in the absence of an SCI in the lumbosacral intumescence, was compatible with spinal shock diagnosis, which can be associated with disk herniation (34).

All subjects demonstrated a neurogenic bladder observed at admission, which was compatible with SCI neuro-localization: cranial to the spinal cord segment S1 or cranial to the L4 vertebra, resulting in increased urethral resistance and difficulties in vesical expression (35).

This study was performed between November 2017 and January 2020 at the Arrábida Veterinary Hospital Rehabilitation Center after approval by the Lisbon Veterinary Medicine Faculty ethics committee.

Dogs were excluded from this study if they had suspected or confirmed spinal cord neoplasia, myelomalacia phenomenon, meningomyelitis, IVDH Hansen type II, thoracolumbar fibrocartilaginous embolic myelopathy, acute non-compressive nucleus pulposus extrusion, or thoracolumbar myelitis. They were also excluded if they were diagnosed with IVDH Hansen type I but had different neuro-localization and/or had normal/increased withdrawal reflexes. Dogs with T11-L3 IVDH Hansen type I were excluded if they underwent conservative management and/or if they were admitted to the center more than 7 days postoperatively.

\section{Study Design}

Twenty-two subjects were admitted to the study and underwent a neurorehabilitation examination according to clinical history 
and physical and neurologic examination after the owners provided consent.

All subjects had an alert mental status, passive standing posture, diverse postures (kyphosis and scoliosis), upper motor neuron peripheral reflexes with the exception of the withdrawal reflex (absent/decreased in one or both limbs), and cutaneous trunci reflexes present at or below the injury site. Overall, superficial and deep pain perception was present.

Deep pain perception was evaluated in a controlled environment, with respect to movement and noise, with 12-cm Halsted mosquito forceps, in both medial/lateral digits of both pelvic limbs. For a more accurate pain perception examination, this was also tested in the perineal region and at the tip and base of the tail.

Spinal hyperesthesia was also assessed with the correct technique of vertebral column palpation. This technique is performed by placing slight pressure on the vertebral column, placing one hand on the abdominal muscles, palpating throughout the dorsal longitudinal ligament between each spinous process, and between each intervertebral space, in order to activate the nociceptors located in the peripheral fibrous annulus (36).

With the dogs in a standing posture, both pelvic limbs were palpated to compare symmetry and tonus. All dogs showed hypotonicity in the flexor muscle group. Proprioceptive positioning was evaluated in dogs while supported by the examiner.

This study used the Open Field Score (OFS) (37) to quantify recovery of stepping ability and to observe coordination between the thoracic and pelvic limbs.

Videotaping was performed on admission (T0) and 2 weeks later (T1). Dogs were randomized into two groups. Dogs were randomly assigned to groups according to the order of admission in the center, and the first selected dog was designated by a blinded procedure.

Evaluations were performed and recorded each week from T1 (T2 to T6) and at follow-ups (F1, F2, and F3). Videotapes were analyzed and scored by two blinded observers, boardcertified canine rehabilitation veterinarians, and if interobserver disagreement exceeded $20 \%$, a third blinded observer, working at a different institution, performed the same analysis.

Twenty-two dogs were admitted in the study and were subjected to the same protocol of functional neuro-rehabilitation (FNR) during the first 2 weeks. The protocol of FNR included: Underwater treadmill (FNR-UWTM); IES and FES.

After the first 2 weeks, they were allocated to different groups, but two dogs left the study before randomization due to the owners' decision. The remaining twenty dogs $(n=20)$ were separated into the FNR-BWSTT protocol group $(n=10)$ and the FNR-COGI protocol group $(n=10)$. Both groups performed these protocols during the next 2 weeks and had outcomes observed at T2 and T3, based on neurological examination and OFS inter-observer observations.

The group with the lower success rate after these first 4 weeks of FNR, was transferred to the protocol with higher results, and evaluations were performed at T4, T5, and T6. As can be seen in Figure 1 the diagram of this study within a 7-week period is

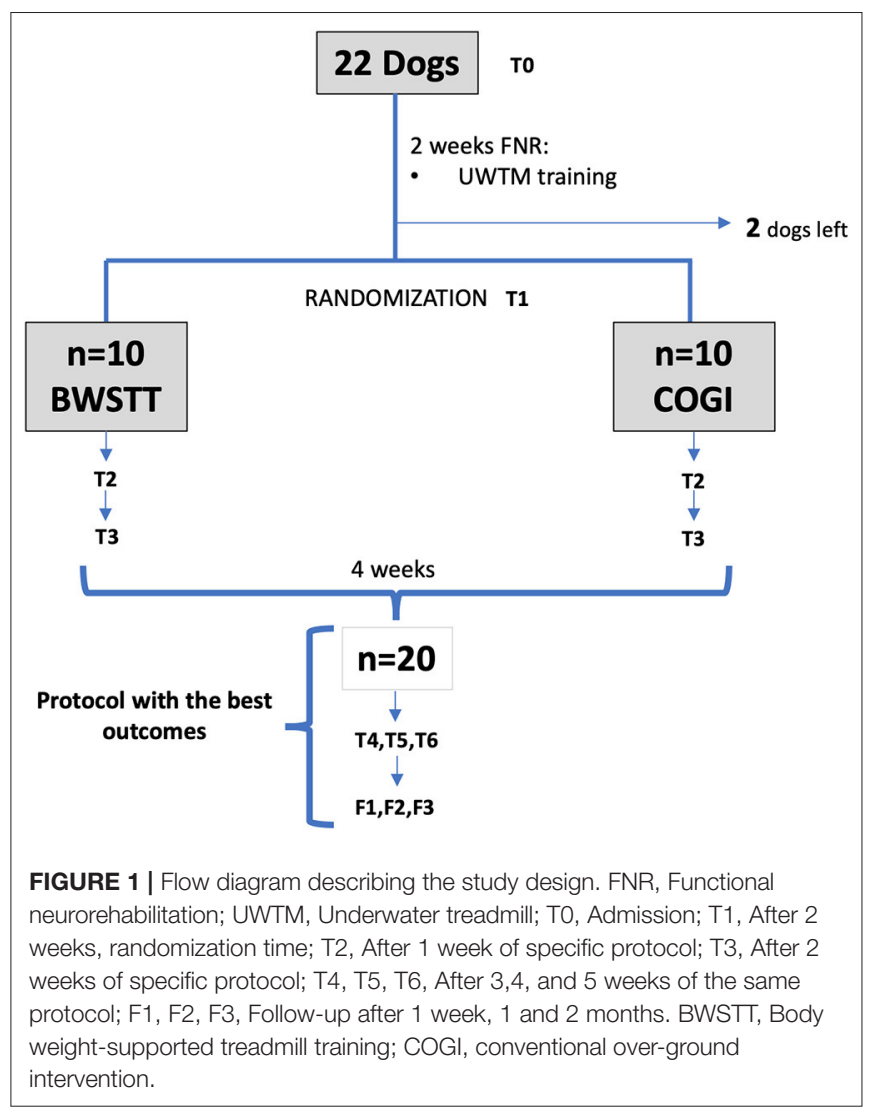

described and explains the 2-week interval between T0 and T1, and also the evaluations at T2 (3rd week), T3 (4th week), T4 (5th week), T5 (6th week), and T6 (7th week).

\section{Interventions}

The 22 dogs that were included in the study started the FNRUWTM protocol within $24 \mathrm{~h}$ after admission. The 1 st day was considered an adaptation to all neurorehabilitation interventions.

\section{FNR-UWTM Protocol}

In the first 2 weeks (T0-T1), all dogs received interferential electrical stimulation (IES) for pain management throughout a 4-channel electrotherapy device (BTL-5645 PULS, BTL, USA). IES is a pre-modulated interferential current commonly used in canine rehabilitation.

This technique used two different channels with four rubber and carbon electrodes $(7 \times 5 \mathrm{~cm})$ (BTL, USA) placed crossing each other at a $90^{\circ}$ angle and located proximately two spaces cranial and caudal to the spinal hyperesthesia site, after clipping the hair and application of gel (Figure 2). The current applied was biphasic, symmetric and continuous and was performed two times/day, 5 days/week in the 1 st week. On the 2 nd week this was applied once a day, each $48 \mathrm{~h}$. Pain level was assessed daily by a correct technique of vertebral column palpation and recorded to better evaluation in slow motion mode.

Current parameters were applied as followed: 


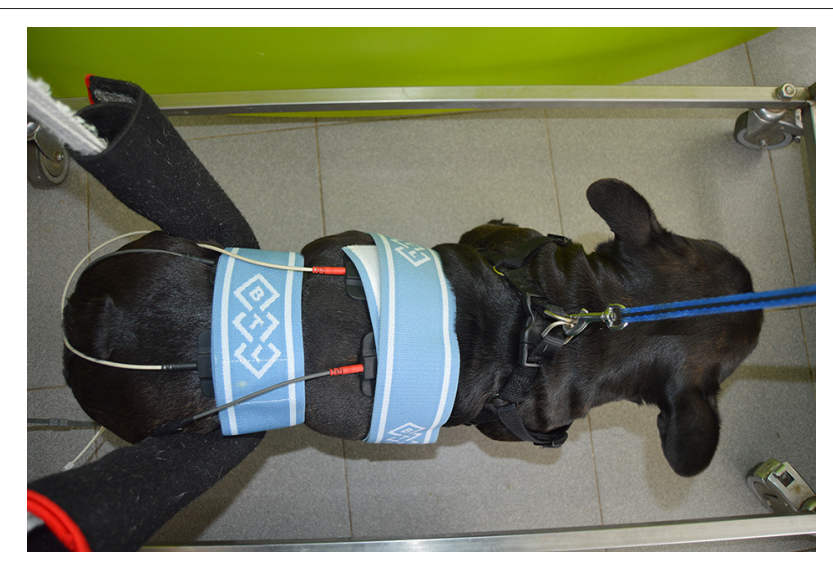

FIGURE 2 | Interferential electrical stimulation (IES) for pain management in postural standing position. Application of two different channels with four electrodes in a crossed position.

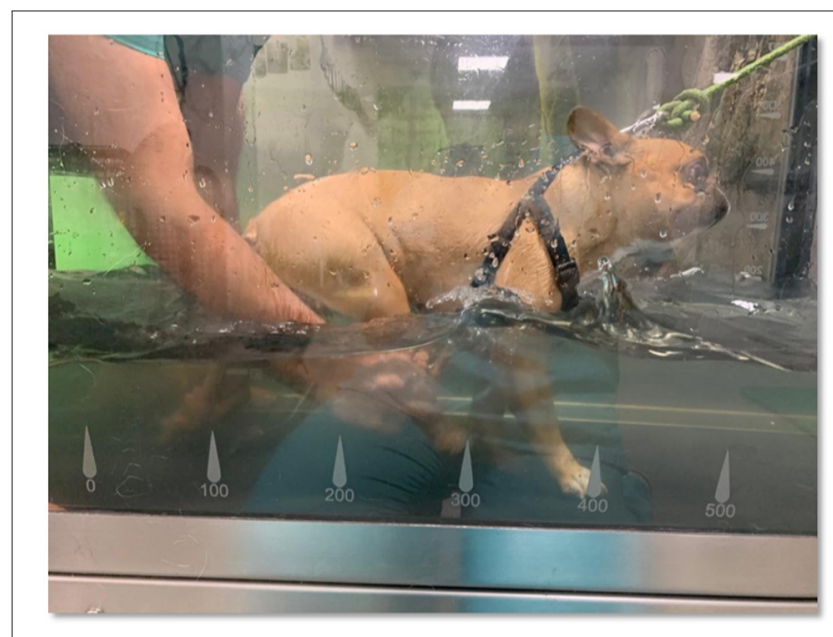

FIGURE 3 | Underwater treadmill locomotor training, with pelvic limb bicycle movements performed by the technician.

- Channel 1 (Acute pain)-Frequency was $80-150 \mathrm{~Hz}$; Intensity was $0.5-1 \mathrm{~mA}$; Pulse duration was $2-50 \mu \mathrm{s}$; Time of treatment of $10 \min (38,39)$;

- Channel 2 (Chronic pain)-Frequency was 1-10 Hz; Intensity was $0.5-1 \mathrm{~mA}$; Pulse duration was 100-400 $\mu \mathrm{s}$; Time of treatment of $10 \mathrm{~min}(38,39)$.

Participants were also subjected to locomotor training based on repetitive water training, with established pelvic limb bicycle movements, stretching of pelvic limb muscles, and stimulation of cutaneous receptors on the treadmill surface (Figure 3 ). This exercise was alternated with perineal stimulation to obtain the flexion and extension cycles of small amplitude used for paralysis of the hindlimbs (40). All exercises were performed with weight support according to the patient's capacity at the time.

In the 1st days of FNR-UWTM training, each patient was allowed to adapt, with speeds beginning at $\leq 0.8 \mathrm{~km} / \mathrm{h}$ and

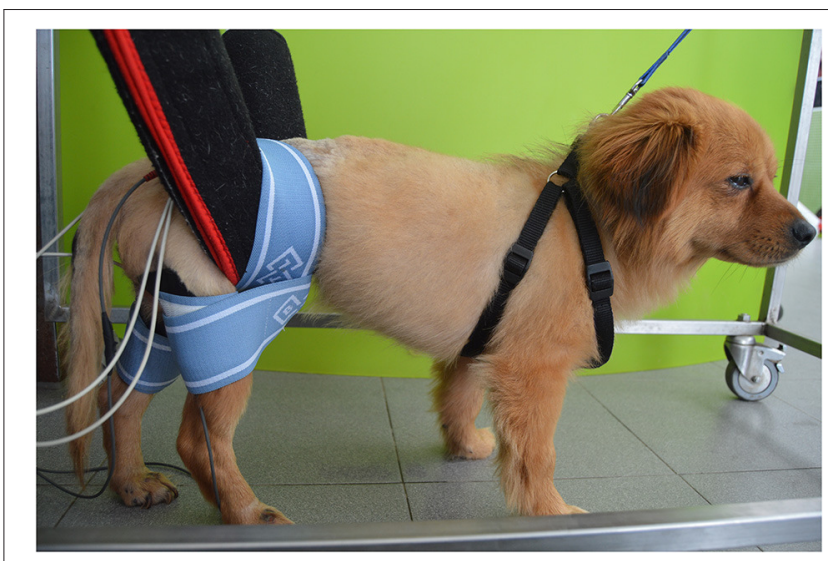

FIGURE 4 | Functional electrical stimulation (FES) through the sciatic nerve. Superficial electrodes applied in a segmental technique, placed on the sciatic nerve root (L7-S1 region) and near the flexor muscle motor point.

progressively increasing to $1.2,1.9$, and $2.5 \mathrm{~km} / \mathrm{h}(41,42)$, first for 3-10 min and extending to $20 \mathrm{~min}$ once a day within the first 2 weeks.

Water temperature was maintained between 24 and $26^{\circ} \mathrm{C}$, and the water level was positioned between the lateral malleolus of the tibia and the lateral condyle of the femur (43). Dogs were monitored by assessing the mucous membranes, capillary refill time, and pulse.

The use of combined approaches in rehabilitation may be more effective than a single intervention, simultaneously targeting different injury mechanisms (44). Therefore, all participants underwent FES within this period with a 2-channel electrotherapy device (BTL-5645 PULS, BTL, USA).

FES is described to use low pulse frequency electrical currents to restore motor functions after SCI, promoting control standing, balance, posture and gait training. Also, increase tonus in the hamstring muscle and polysynaptic reflex (45), essential in this population of dogs that showed decreased or absent withdrawal reflexes.

Superficial rubber and carbon electrodes $(7 \times 5 \mathrm{~cm})(\mathrm{BTL}$, USA) were applied after trichotomy in a segmental technique and were placed over the peripheral nerve trunk and motor point (46) with patients in the standing position (Figure 4). Thus, the main hamstring muscles were stimulated (biceps femoris, semitendinosus and semimembranosus), both cranial and caudal groups, allowing the stimulation of the stance and swing phase, respectively.

This was a symmetric, biphasic and pulsed alternating current with the following parameters: Frequency of $30 \mathrm{~Hz}$ (47); intensity of 6-16 mA (48); pulse duration 100-150 $\mu$ s (49); duty cycle 1:4 ratio, 2-4s ramp-up, $8 \mathrm{~s}$ on-time, 1-2 s ramp-down (38), and time of treatment of $10 \mathrm{~min}$. FES was performed 2-3 times/day for 5 days/week.

During treatment, parameters were adjusted according to the monitoring of muscle fatigue signs, such as muscle weakness, fasciculations, increased respiratory rate and/or pain. In case any of these signs appeared, parameters were adjusted: intensity (mA) 


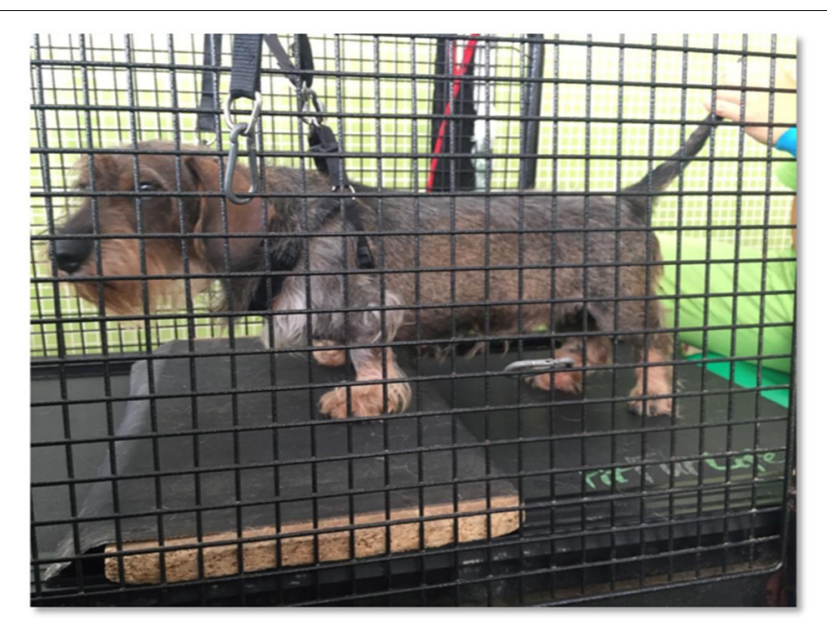

FIGURE 5 | Body weight-supported treadmill training with bipedal step training. Forelimbs stationary on a fixed platform above the belt.

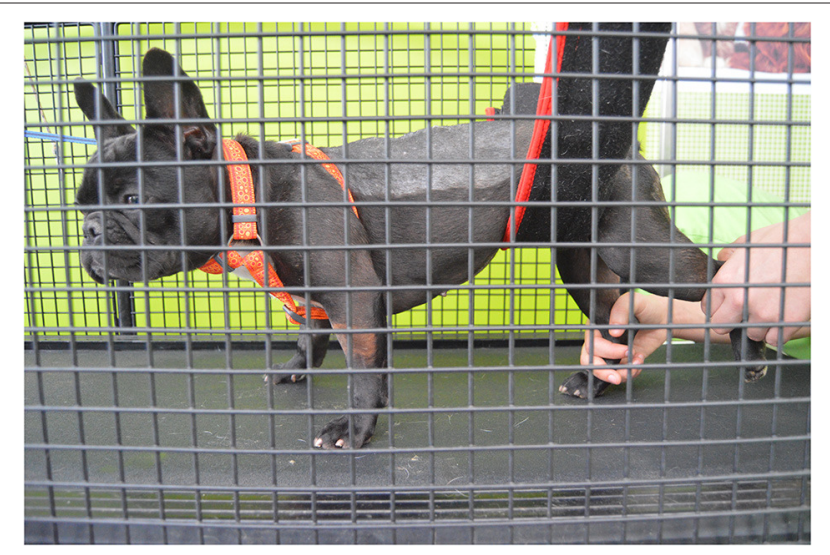

FIGURE 6 | Body weight -supported treadmill training with quadrupedal step training. Technician preforming bicycle movements.

was reduced until they disappear and if they continued, frequency $(\mathrm{Hz})$ was also reduced. Also, if they persist in time, duty cycle was increased (i.e., until 1:6).

\section{FNR-BWSTT Protocol}

In human medicine, BWSTT can be manually or robotically assisted, such as via the Lokomat system, which supports $60 \%$ of an individual's weight at the beginning, decreasing in accordance with load tolerance to no $<25 \%$ support (50). A similar manual support approach was implemented in our dogs.

As all dogs were acclimated to the underwater treadmill, very few dogs resisted treadmill training. However, in dogs that offered resistance, bipedal step training was required, wherein the forelimbs remained stationary on a fixed platform above the belt (51) (Figure 5).

The aim of the BWSTT protocol was to achieve quadrupedal step training, starting with:

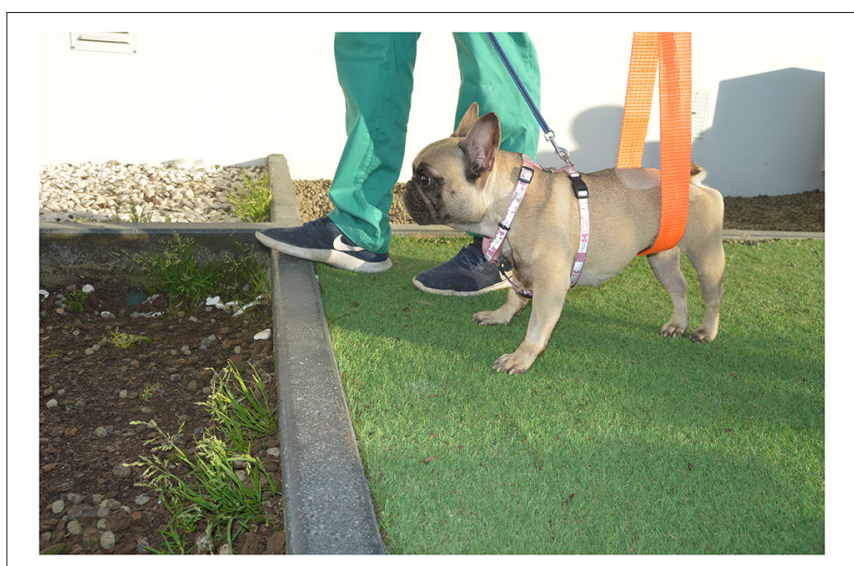

FIGURE 7 | Conventional over ground intervention. Gait Stimulation in different floors surfaces, such as sand, stones, and grass.

- Speeds of $1-2.5 \mathrm{~km} / \mathrm{h}$, during 20-30 $\mathrm{min}, 2-3$ times/day, 6 days/week according to patients' capabilities (Figure 6) (5254);

- The treadmill slope was elevated from 10 to $25^{\circ}$, with thoracic and pelvic limb coordination $(55,56)$.

All 10 dogs in this group underwent BWSTT within a therapeutic window of $40 \mathrm{~min}$ after application of FES, using the same technique as described earlier.

During these 2 weeks (T1-T3) it was performed the FNRBWSTT protocol without alteration regarding time, frequency during the day and frequency during the week. Thus, the locomotor training had a total range from 40 to 90 min plus 20-30 min of FES in a daily basis.

\section{FNR-COGI Protocol}

At the same time (T1-T3), COGI was applied in 10 dogs, by one or two veterinarians' technicians, with the help of a harness system that allowed the dogs to perform step movements with similar weight support as described before, decreasing the load tolerance according to dogs' abilities.

During gait stimulation, all dogs had to touch the floor surface, beginning with a knuckling position and progressing to cutaneous receptor stimulation (placed in the interdigital space).

Dogs were stimulated to walk for 20-30 min, 2-3 times/day, 6 days/week on different floor surfaces, such as sand, stones, and grass (Figure 7).

After the dogs achieved a flexion-extension locomotor pattern, it was associated with gait stimulation on an uneven floor as well as up and down ramps (Figure 8), for the same amount of time.

All 10 dogs were subjected to the same FES protocol (Table 1) before they were stimulated to walk. Dogs performed a daily locomotor training from 40 to $90 \mathrm{~min}$ total and 20-30 min of FES during these 2 weeks.

Thus, in both protocols (COGI and BWSTT), exactly the same time of CNS stimulation was promoted. 


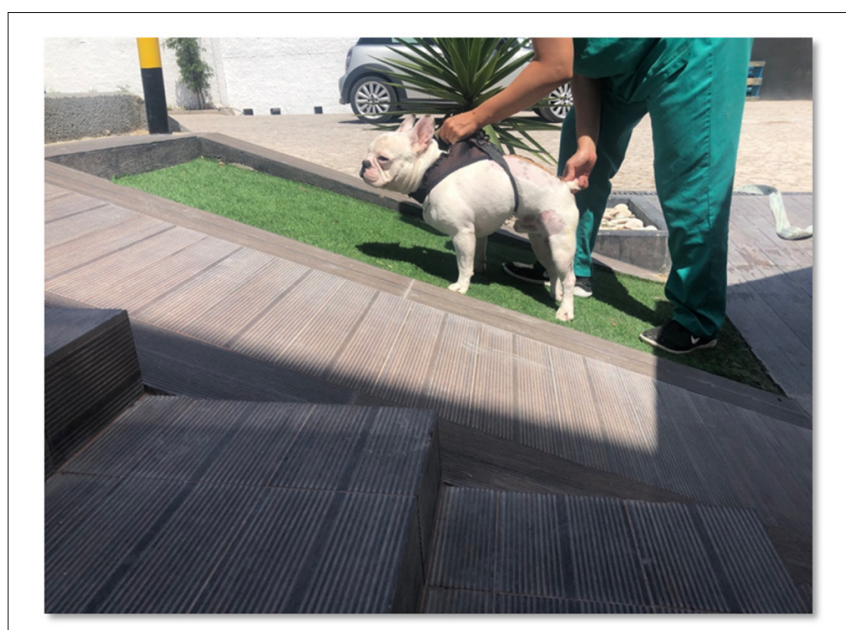

FIGURE 8 | Gait Stimulation on uneven floor, such as ramp up and down.

TABLE 1 | Functional Electrical Stimulation (FES) protocol.

\begin{tabular}{lc}
\hline Current & Symmetric \\
& Biphasic \\
& Pulsed \\
Frequency & $30 \mathrm{~Hz}$ \\
Intensity & $6-16 \mathrm{~mA}$ \\
Pulse duration & $100-150 \mu \mathrm{s}$ \\
Duty cycle & $1: 4$ \\
Shape & $2-4$ s ramp-up, 8s on-time, 1-2 s ramp-down \\
Time of treatment & $10 \mathrm{~min} ; 2-3$ times/day for 5 days/week \\
\hline
\end{tabular}

\section{Supportive Care}

Dogs were hospitalized full-time, resting in soft beds to avoid pressure sores or decubital ulcers, and doughnut bandages were placed under bone prominences. If they were recumbent, they were turned every $4-6 \mathrm{~h}$ from left to right lateral recumbency to prevent atelectasis or accumulation of lung secretions (57). They were always encouraged to maintain sternal recumbency.

Dogs were fed three times per day with an intake of $30 \%$ and hydric support of 100-120 ml $/ \mathrm{kg}$. All had neurogenic bladders, which were expressed every $4-6 \mathrm{~h}$ as a daily rule $(57,58)$.

\section{Outcomes/Follow-Ups}

All dogs underwent an FNR examination and an OFS evaluation every 7 days. The first evaluation was performed at admission (T0), followed by an evaluation at 2 weeks after initiating FNRUWTM (T1). At this stage, the presence of the withdrawal reflex and crossed extensor reflex was evaluated, as the main outcome.

Blinded randomization was implemented at $\mathrm{T} 1$, when the dogs were divided into two groups: the BWSTT group and the COGI group. Evaluations were performed weekly over the subsequent 5 weeks (T2-T6), finishing the study within a 7week period.

If neurological evolution was not evident in one of these groups until the finish of $\mathrm{T} 3$, the protocol was switched to the one that yielded the best apparent results. Thus, from T4 to T6, all dogs were treated with the same FNR protocol.

Follow-up was advised after the 1st week of release, also after 1 and 2 months. All were evaluated (FNR exam and OFS score) and videotaped.

In this study, functional outcome was considered when dogs achieved an OFS score classification of $\geq 11$. An OFS of 11 is equivalent to a locomotor state in ambulatory paraparesis and OFS $>11$ is equivalent to that in proprioceptive ataxia. A functional state can be defined as the possibility of a dog standing up, maintaining an active standing posture, giving five or more steps, and having the ability to urinate and defecate voluntarily.

\section{Statistical Analysis}

Quantitative, qualitative, and categorical data were analyzed using IBM SPSS Statistics software, Version 22 (International Business Machines Corporation, Armonk, NY, USA), and the results were interpreted at a level of significance of $p<0.05$.

For inter-observer validation regarding OFS scores, normality tests were performed, and normality was not verified. Thus, independent-samples Mann-Whitney $U$-tests were performed.

For comparison between groups and between evaluation time-points, a univariate analysis of variance was performed. The statistical model was considered significant $(p<0.001)$. Estimated marginal means with $95 \%$ confidence interval and an interaction plot for the comparison of mean OFS at each time-point between groups were derived.

Also, for better evaluation between T1 and T3, a two-way repeated measures ANOVA with time as a repeated measure, was performed. Thus, a measured dependent variable (OFS) was evaluated regarding two independent variables (time points and different protocols), with the primary purpose of understanding if there is an interaction between these two factors on the dependent variable.

\section{RESULTS}

This study described the evolution of progress in 22 dogs throughout their FNR protocol over a 7-week period, according to the diagram in Figures 9, 10, and their evaluation using the OFS score.

In the total population $(n=22)$, the average age was 5.3 years and average weight was 9.65 . There were 10 males and 12 females; $63.6 \%(14 / 22)$ were chondrodystrophic dogs and $36.4 \%(8 / 22)$ of non-chondrodystrophic dogs. The following was the breed distribution: six Dachshunds, four French Bulldogs, four Mixed breeds, two Beagles, two Basset Hounds, one Labrador Retriever; one Pincher; one Yorkshire Terrier; and one German Shepherd. Before randomization, two dogs left the study, of which one was Dachshund and one was a German Shepherd.

All dogs had spinal hyperesthesia at admission and were under the IES protocol. At T1 no dog had pain in both groups (COGI and BWSTT), which was assessed by palpation and recorded in slow motion mode.

After randomization (T1), dogs were divided into two groups ( $n=10$ each), with similar chondrodystrophy, age, and average weight. 


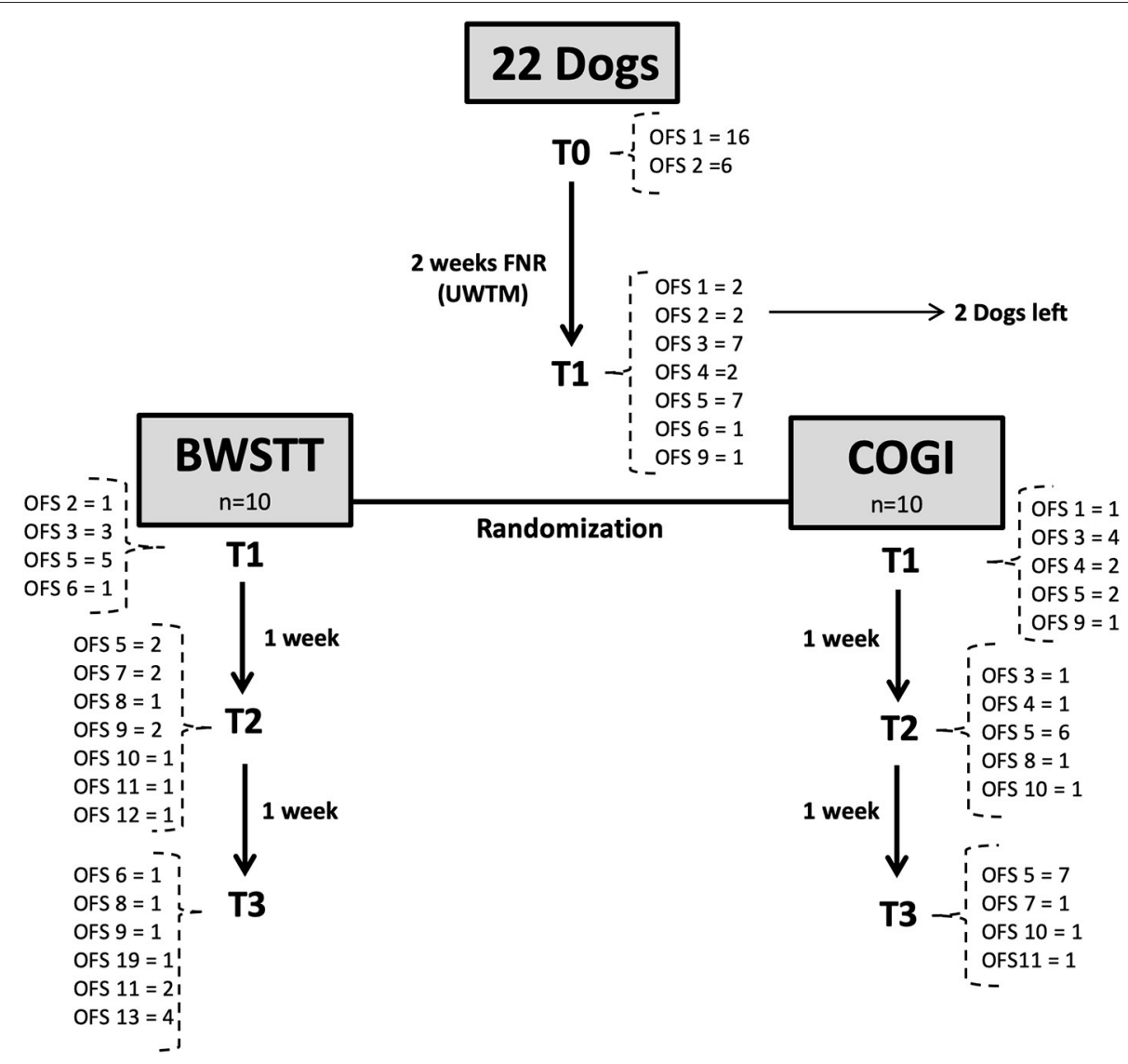

FIGURE 9 | Flow diagram describing the neurologic evolution of the 22 dogs. FNR, Functional neurorehabilitation; UWTM, Underwater treadmill; TO, Admission; T1, After 2 weeks, randomization time; T2: After 1 week of specific protocol; T3, After 2 weeks of specific protocol; BWSTT, Body-weight supported treadmill training; COGl, conventional overground intervention.

For inter-observer validation, independent-samples MannWhitney $U$-tests were performed, revealing the absence of a statistical difference between observers in every moment of evaluation ( $p=0.799)$.

In the total of 156 observations, that were performed and recorded between the two observers, there were only 21 inconsistencies, resulting in 13\% inter-observer disagreement.

For comparison between groups and between evaluation timepoints, a univariate analysis of variance was performed. The statistical model was considered significant $(p<0.001)$, with statistically significant differences between all OFS evaluation time-points $(p<0.001)$ and between groups (COGI $\times$ BWSTT) $(p<0.001)$. Both variables (group and time-point) also demonstrated a positive interaction $(p=0.019)$.

A higher mean OFS was observed in the BWSTT group (10.132) than in the COGI group (8.001) (Table 2).

In particular in T2 and T3, at each evaluation point there was a higher mean of OFS in the BWSTT group (Table 3). Additionally, it can be observed that, at 4 weeks after admission (T3), FNRBWSTT dogs showed a borderline functional outcome (OFS $\geq$ 11), which was only demonstrated in the COGI group at T6 (after 7 weeks).
At $\mathrm{T} 3$, the functional outcome (OFS $\geq 11$ ) was achieved within the BWSTT group in six dogs and in the COGI group in only one dog. The functional outcomes at the subsequent timepoints (T4, T5, and T6) are described in Figure 11. In addition, at T3, the best result was seen in the BWSTT group, with four dogs classified as OFS 13, while one dog in the COGI group achieved only OFS 11.

Before T4 evaluation, one dog left the study by the owners' decision, thus the number of dogs decreased $(n=19)$, as shown in the flow diagram (Figure 10).

A two-way repeated measures ANOVA that compared the OFS mean differences between groups from T1 to T3 was done and the interaction plot obtained is shown in Figure 12. There was an interaction effect between time and treatment, thus OFS my vary based on time differently between the two treatments. Thus, there was a clear difference between the estimated mean of OFS after T1, with the highest difference observed at T3. According to the multivariate tests there was clear statistical significance between groups regarding treatment $(p=0.006)$ and during each evaluation time point $(p=0.000)$.

Upon medical discharge at the 7 th week, a total functionality of $90 \%$ was achieved (17/19). Within the groups, functionality 


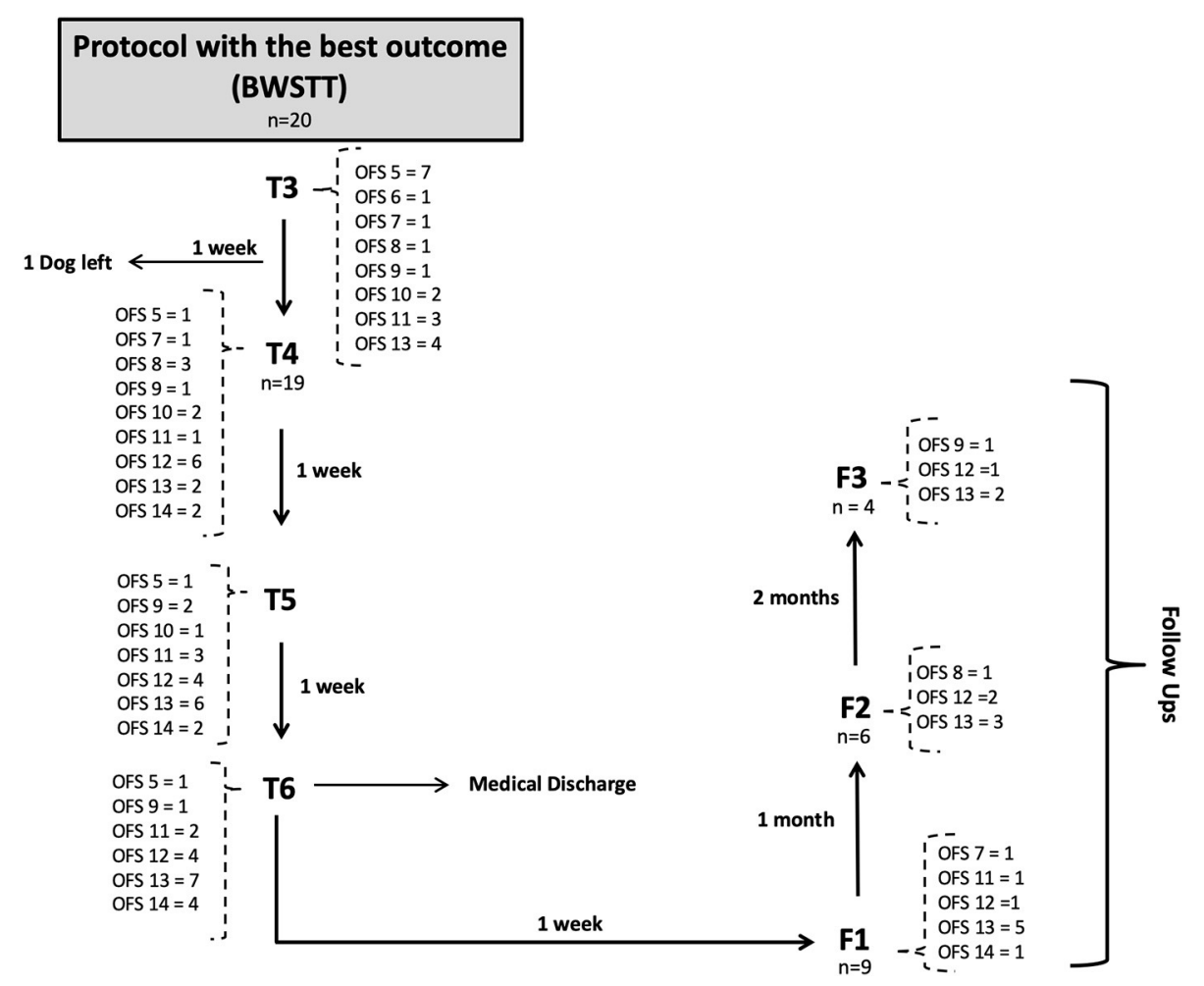

FIGURE 10 | Flow diagram describing the neurologic evolution of the 22 dogs. FNR, Functional neurorehabilitation; T4, T5, T6,After 3,4 and 5 weeks of the same protocol; F1, F2, F3, Follow-up after 1 week, 1 and 2 months; BWSTT, Body-weight supported treadmill training; COGl, conventional overground intervention.

TABLE 2 | OFS total mean between BWSTT and COGI groups.

\begin{tabular}{lcccc}
\hline Group & OFS mean & Std. error & \multicolumn{2}{c}{$\mathbf{9 5 \%}$ confidence interval } \\
\cline { 4 - 5 } & & & Lower bound & Upper bound \\
\hline BWST & 10.132 & 0.249 & 9.640 & 10.623 \\
COGI & 8.001 & 0.247 & 7.512 & 8.490 \\
\hline
\end{tabular}

OFS, Open Field Score; BWSTT, Body weight-supported treadmill training; COGl, Conventional overground intervention.

was $78 \%(7 / 9)$ in the COGI group by the 7 th week, and $100 \%$ $(10 / 10)$ in the BWSTT group but already demonstrating these results in the 6th week (Figure 11).

Thus, for the COGI group, functional outcomes were achieved within a mean time of 6.1 weeks (range, $4-8$ weeks) and for the BWSTT group within a mean time of 4.6 weeks (range, 3-6 weeks).

\section{DISCUSSION}

Our study population characterization agrees with that of most documented studies on IVDH Hansen type I, which report that the Dachshund is the breed most frequently diagnosed with this disease (59-63), followed by the French bulldog $(64,65)$. The main reason for this was explained by Hansen $(66,67)$ as involving transformation of the gelatinous nucleus pulposus into
TABLE 3 | T2 and T3 OFS evaluation in both groups.

\begin{tabular}{llcccc}
\hline OFS moment & Mean & Std. error & \multicolumn{2}{c}{$\mathbf{9 5 \% \text { confidence interval }}$} \\
\cline { 5 - 6 } & & & Lower bound & Upper bound \\
\hline T2 & BWSTT & 8.300 & 0.589 & 7.136 & 9.464 \\
& COGI & 5.500 & 0.589 & 4.336 & 6.664 \\
T3 & BWSTT & 10.700 & 0.589 & 9.536 & 11.864 \\
& COGI & 6.300 & 0.589 & 5.136 & 7.464 \\
\hline
\end{tabular}

OFS, Open Field Score; BWSTT, Body weight-supported treadmill training; COGI, Conventional overground intervention.

hyaline cartilage, which can begin as early as 2 months of age in Dachshunds and French Bulldogs.

In addition, chondrodystrophic breeds were the majority with $64 \%(14 / 22)$, in agreement with Kinzel et al. (68), and Aikawa et al. (5). However, $36.4 \%(8 / 22)$ were non-chondrodystrophic dogs, such as the German Shepherd and Labrador Retrievers, as described by Jeffery et al. (11) and Dewey and da Costa (36). The most frequent localization was the thoracolumbar region (69).

The average age of the affected dogs was 5.3 years, similar to that reported in previous studies $(8,62,70)$, and the average weight was $9.65 \mathrm{~kg}$, which was similar to that reported in earlier studies $(65,71,72)$.

Chondroid metaplasia was an inclusion criterion. According to Ball et al. (73) and Thomas et al. (74), this should have 


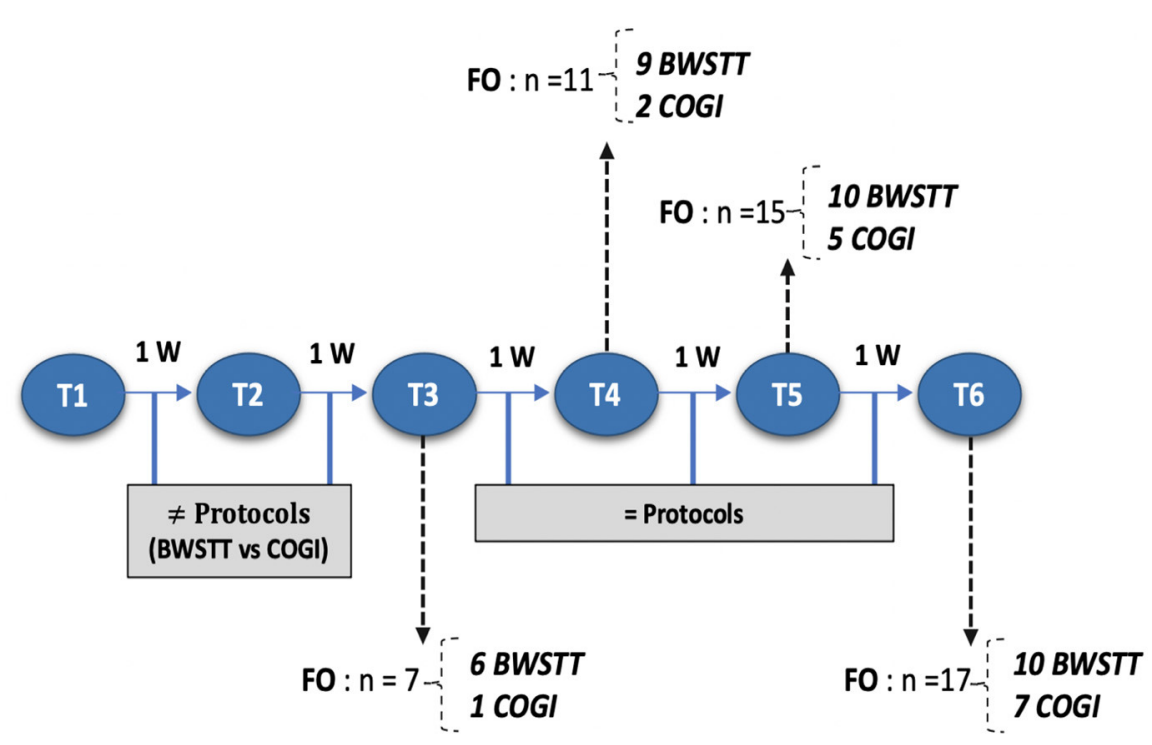

FIGURE 11 | Flow diagram describing each moment according to number of weeks and functional outcome recovery. FNR, Functional neurorehabilitation; UWTM, Underwater treadmill; T1, After 2 weeks, randomization time; T2, After 1 week of specify protocol; T3, After 2 weeks of specific protocol; T4, T5, T6, After 3,4, and 5 weeks of the same protocol; BWSTT,Body-weight supported treadmill training; COGI, conventional overground intervation; FO, Functional outcome.

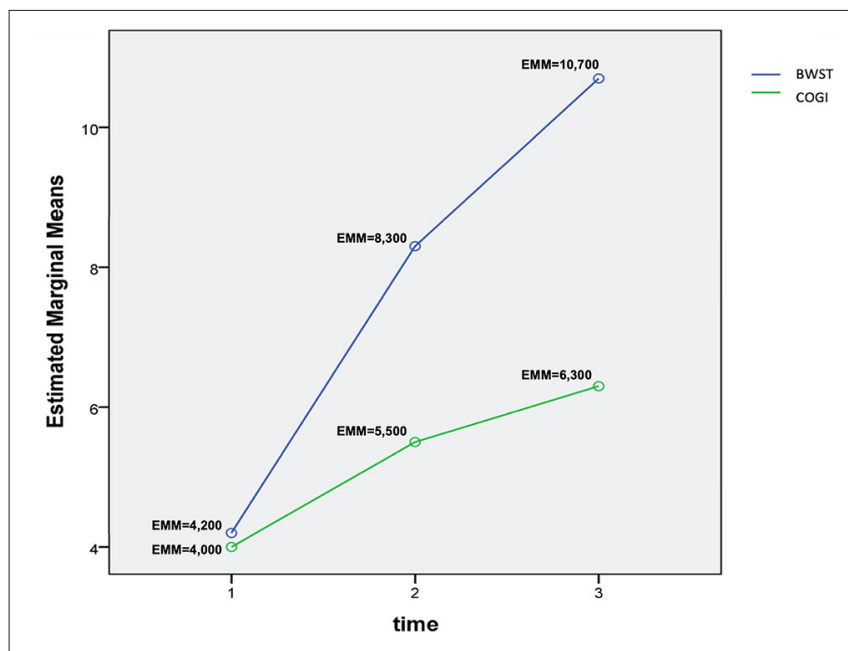

FIGURE 12 | Interaction plot describing the evolution of OFS means in T1, T2, and T3 between groups. OFS, Open Field Score; BWSTT, Body weight-supported treadmill training; COGl, Conventional overground intervention; EMM, Estimated marginal means.

demonstrated skewing of the sample population to males, but in our study, 55\% (12/22) were females.

In T0, the 22 dogs started the FNR-UWTM protocol based on the IES technique to manage spinal hyperesthesia and locomotor training during 2 weeks. Spinal hyperesthesia manifestation decreased during this time (T0-T1), in particular in the 2 nd week, and IES application was performed according to the pain level assessed by a correct technique of vertebral column palpation.

The repetitive locomotor training allowed stimulation of the muscle spindle and the cutaneous receptors during the bicycle movements performed by the technician, under water, in direct contact with the treadmill surface (22).

The treadmill locomotor training in incomplete SCI patients can induce plasticity in reflex pathways (75-77), as proven by Gossard et al. in incomplete SCI cats, who obtained functional plasticity of the locomotor CPGs (16).

The main goal of the FNR-UWTM training was to acquire the flexion-extension pattern before randomization (T1), equivalent to a minimum classification of OFS 3. In our study, this was not achieved in all dogs. Two dogs left the study before achieving this pattern (one with OFS 1; and one with OFS 2) while the remainder were randomly divided into the BWSTT and COGI groups (Figure 1).

At $\mathrm{T} 1$, the population was assigned to two groups (FNRBWSTT $\times$ FNR-COGI) and dogs were evaluated, by two blinded observers using the OFS, resulting in a total of 156 observations with only $13 \%$ interobserver disagreement, confirming the reliability of the results obtained in the evaluations.

By a univariate analysis of variance, it was observed that after T1, both the BWSTT group and the COGI group showed a positive evolution over time in terms of an increase in OFS mean values $(p<0.001)$. Also, a two-way repeated measures ANOVA was performed to carefully evaluate from T1 to T3 and a similar significance was obtained $(p=0.007)$.

It is the authors opinion that just like in human medicine, repetitive step training for several consecutive weeks (by BWSTT or underwater treadmill) promotes an increase in muscle force output and endurance as well as an increase in rhythmic activity by the spinal locomotor circuitry and stimulation of remnant descending/ascending pathways (15). This selects the activation of motor neuron populations to obtain muscle synergy by descending motor pathway control and afferent 
input modulation, proposing rehabilitation strategies as a toll to improve stepping recovery after SCI (78).

Therefore, the limb displacement compensation mechanism, which involves increasing the hip angle, can cause activation of adductor muscles, and decreasing the angle can promote activation of the abductor muscles (79). In addition, the limb load compensation mechanism, which can stimulate stretch receptors and the Golgi tendon organs of extensor muscles, allows for faster rehabilitation in animal models $(40,80)$ and in humans $(81,82)$.

The interaction plot documented the biggest difference in the estimated means of OFS between groups in T3 (Figure 11), with an average of 10.7 in the BWSTT and 6.3 in the COGI groups (Table 2). In addition, the first time-point for assessing the difference between groups was at T2 (at 1 week after initiating differentiated training) with a clear distinction between them, this difference was maintained until T5, after 2 weeks of the same BWSTT training was implemented for ethical reasons.

At T5, the estimated OFS confidence interval showed an overlap of the upper limit of the COGI dogs and the lower limit of the BWSTT dogs, and functionality at this stage was considered to be $79 \%(15 / 19)$.

At the time of clinical discharge (T6), functional recovery was achieved in $90 \%(17 / 19)$ of all dogs and $100 \%$ had recovered bladder function. Within the BWSTT group, $100 \%(10 / 10)$ of the dogs recovered, while only $78 \%$ (7/9) in the COGI group recovered. The functional outcomes at the time of clinical discharge (90\% functional recovery) agreed with the results of previous studies $(1,4,8,14,73)$. However, in the BWSTT group, there was $100 \%$ functional recovery within an average time of 4.6 weeks. Considering that these dogs had severe grade I MFS, this protocol is a viable tool for implementation in sub-acute postsurgical IVDH dogs.

The results obtained in this population of subacute postsurgical IVDH dogs that had absent/decrease withdrawal reflex at admission, and a consequential descending pathway blockage compatible with spinal shock, showed that the underwater treadmill training could have promoted the appearance of the flexion/extension pattern. Also, the allocation of dogs in different groups demonstrated that in the BWSTT a functionality of $100 \%(10 / 10)$ was achieved within a mean time of 4.6 weeks, while in the COGI group 78\% (7/9) were functional within 6.1 weeks, suggesting that even spontaneous recovery could occur in both groups, the BWSTT had the major success in recovery and in less time.

Recovery of function due to neurological injuries can be variable and difficult to predict. The most important challenge for the recovery of function is axonal regeneration and the formation of new functional synapses across the injury site (62, 83), mainly between the axons of damaged tracts and the new collateral axons (84). Thus, locomotor training is a strategy that promotes cutaneous reflex excitability (85). These can result from different mechanisms, involving the sprouting of undamaged fibers, regeneration of damaged fibers, and/or changes in synaptic efficiency $(86,87)$.

In humans BWSTT allows for greater trunk stabilization, a rhythmic timing exercise, and also assists with retropulsion of the stance phase, which promotes the hip extension critical to the initiation of the swing phase (88). Moreover, the combination of BWSTT and FES clearly improved walking speed, distance, limb coordination, strength, and muscle activation patterns (29). This combination showed significant improvements in cadence and step length and had a synergistic effect on muscle mass, balance, coordination, and rhythm. Complementary FES with low pulse frequency has been recommended for humans with incomplete SCI, probably because it facilitates training in standing $(31,46)$.

FES may also have been essential for its action in muscle atrophy and fatigue (89). Following SCI there are proportionally more fibers type II (fast-fatigable, anaerobic) than type I (slow, aerobic), which are also atrophied, leading to weakness and fatigue. This atrophy is also accompanied by a conversion of type I to type II muscle fibers. Thus, FES technique can increase contraction time and resistance to fatigue by reversing the muscle mass loss and the conversion of muscle fibers to a different type, probably resulting in more muscle fibers that become type I $(90,91)$. It also increases capillary density and blood flow, decreases spasticity and pain, increases the range of motion, and decreases contractures (92-95).

Research indicates that BWSTT promotes greater control of body posture and balance, both of which depend on organization of the multisensory system (96) and recruitment of muscles in the categories of the flexors/extensors and abductors/adductors (97). This may be among the main reasons for the faster recovery of dogs in the BWSTT group and also for the positive recovery of dogs who had been treated with the COGI protocol initially, but were switched to the BWSTT protocol. This last protocol leads to an increase in the amplitude and coordination of motor unit firing in leg muscles (23).

Our results indicated that COGI training could not promote as many repetitive exercises as BWSTT. For improved walking function, motor learning requires more than a simple repetition (20) and benefits from the opportunity to make and correct errors. This facilitates recovery of locomotion after incomplete SCI $(17,98)$.

Nevertheless, COGI dogs showed slow recovery, with positive evolution, probably due to the effects of walking training on the cutaneous muscular reflex, which comprises part of the flexor afferent pathway. This pathway is considered to be activated by excitatory and inhibitory interneurons within the CPGs (99).

In humans with incomplete SCI, it was reported no difference between BWSTT and COGI interventions. Likewise, no distinctions between the two approaches were seen from the kinematic and kinetic aspects $(24,28)$. This was not the case in our study, where BWSTT showed a markedly better performance. In human medicine, the combination of these types of training is considered to be beneficial (100). This is likely due to the ability of BWSTT to stimulate the stance phase and promote hip, knee, and ankle control, while COGI training allows integrated volitional control of all components of gait (101).

The biggest limitation of this study was the absence of a kinematic and kinetic evaluation, as well as electromyographic studies useful for neuromuscular monitoring, which could promote understanding of the differences between the groups. In addition, the decrease in the number of dogs that attended the 
first follow-up $(n=10)$ did not allow reliable assessment of the efficacy of these protocols in the long term. Finally, this study was also limited by the fact that dogs only differed in treatment for 2 weeks, as all dogs were transferred to the protocol with best results in T3 (BWSTT), which could be the cause of the overall differences between groups to be relatively small. Given these, further studies are warranted.

The difficulty in comparing differences between both groups is probably due to the fact that the dogs underwent different treatment for only 2 weeks.

\section{CONCLUSION}

The differences in successful recovery between the BWSTT group and the COGI group were clearly demonstrated in this study. After 4 weeks of the FNR implementation $60 \%(6 / 10)$ had recovered in the BWSTT group, while $10 \%(1 / 10)$ had recovered in the COGI group.

Despite these differences, dogs in the COGI group managed to evolve positively, primarily after switching to the BWSTT protocol. This may suggest that conventional protocols can be applied to dogs with incomplete SCI, but can delay functional recovery, while treating dogs with SCI by BWSTT can yield better functional outcomes in less time.

Both protocols, which included FES and locomotor training, were considered to be safe and not harmful to any of the dogs, and promoted a positive evolution in dogs with grade I MFS incomplete SCI, diagnosed with T11-L3 IVDH Hansen type I,

\section{REFERENCES}

1. Olby N, Levine J, Harris T, Muñana K, Skeen T, Sharp N. Long-term functional outcome of dogs with severe injuries of the thoracolumbar spinal cord: 87 cases (1996-2001). J Am Vet Med Assoc. (2003) 222:762-9. doi: 10.2460/javma.2003.222.762

2. Levine J, Levine G, Porter B, Topp K, Noble-Haeusslein L. Naturally occuring disk herniation in dogs: an opportunity for pre-clinical spinal cord injury research. J Neurotrauma. (2011) 28:675-88. doi: 10.1089/neu.2010.1645

3. Moore SA, Early PJ, Hettlich BF. Practice patterns in the management of acute intervertral disc herniation in dogs. J Small Anim Pract. (2016) 57:409-15. doi: 10.1111/jsap.12496

4. Langerhuus L, Miles J. Proportion recovery and times to ambulation for non-ambulatory dogs with thoracolumbar disc extrusions treated with hemilaminectomy or conservative treatment: a systematic review and meta-analysis of case-series studies. Vet J. (2017) 220:2-34. doi: 10.1016/j.tvjl.2016.12.008

5. Aikawa $T$, Fujita $H$, Kanazono S, Shibata M, Yoshigae $Y$. Longterm neurologic outcome of hemilaminectomy and disk fenestration for treatment of dogs with thoracolumbar intervertebral disk herniation: 831 cases (2000-2007). J Am Vet Med Assoc. (2012) 241:1617-26. doi: 10.2460/javma.241.12.1617

6. Brisson BA. Intervertebral disc disease in dogs. Vet Clin Small Anim. (2010) 40:829-58. doi: 10.1016/j.cvsm.2010.06.001

7. Freeman P, Jeffery ND. Re-opening the window on fenestration as a treatment for acute thoracolumbar intervertebral disc herniation in dogs. $J$ Small Anim Pract. (2017) 58:199-204. doi: 10.1111/jsap.12653

8. Loughin CA, Dewey CW, Ringwood PB, Pettigrew RW, Kent M, Budsberg SC. Effect of durotomy on functional outcome of dogs with type I thoracolumbar disc extrusion and absent deep pain perception. Vet Comp Orthop Traumatol. (2005) 3:141-6. doi: 10.1055/s-0038-1632953 after surgery. Future studies should be continued with a focus on longer period times in a single treatment.

\section{DATA AVAILABILITY STATEMENT}

The raw data supporting the conclusions of this article will be made available by the authors, without undue reservation.

\section{ETHICS STATEMENT}

The animal study was reviewed and approved by CEBEAFaculty of Veterinary Medicine. Written informed consent was obtained from the owners for the participation of their animals in this study.

\section{AUTHOR CONTRIBUTIONS}

ÂM was the Certified Canine Rehabilitation Professional (CCRP) examiner/instructor at the University of Tennessee that performed all neurorehabilitation examinations and re-evaluations, and also the major contributor in writing the manuscript. DG and AC were members of the neurorehabilitation team that helped in the protocol execution and manuscript revision. AC was the second observer of this study. IV performed the statistical analysis. ÂM and AF designed the study protocol. AF revised all images recorded regarding the neurorehabilitation examinations with the help of ÓG. All authors have read and approved the final manuscript.

9. Sterna J, Burzykowski T. Assessment of the usefulness of the fenestration method in cases of disc extrusion in the cervical and thoraco-lumbar spine in chondrodystrophic dogs. Pol J Vet Sci. (2008) 11:55-62.

10. Kazakos G, Polizopoulou ZS, Patsikas MN, Tsimopoulos G, Roubies N, Dessiris A. Duration and severity of clinical signs as prognostic indicators in 30 dogs with thoracolumbar disk disease after surgical decompression. $J$ Vet Med. (2005) 52:147-52. doi: 10.1111/j.1439-0442.2005.00698.x

11. Jeffery ND, Levine JM, Olby NJ, Stein VM. Intervertebral disk degeneration in dogs: consequences, diagnosis, treatment, and future directions. J Vet Intern Med. (2013) 27:1318-33. doi: 10.1111/jvim.12183

12. Sims C, Waldron R, Marcellin-Little DJ. Rehabilitation and physical therapy for the neurologic veterinary patient. Vet Clin North Am Small Anim Pract. (2015) 45:123-43. doi: 10.1016/j.cvsm.2014.09.007

13. Bush WW, Tiches DM, Kamprad C, Murtaugh RJ, Barr, CS. Functional outcome following hemilaminectomy without methylprednisolone sodium succinate for acute thoracolumbar disk disease in 51 non-ambulatory dogs. $J$ Vet Emerg Crit Care. (2007) 17:72-6. doi: 10.1111/j.1476-4431.2006.00202.x

14. Olby N, Harris T, Burr J, Muñana K, Sharp N, Keene B. Recovery of pelvic limb function in dogs following acute intervertebral disc herniations. $J$ Neurotrauma. (2004) 21:49-59. doi: 10.1089/089771504772695940

15. Mann F, Wagner-Mann C, Dunphy E, Ruben D, Rochat M, Bartels K. Recurrence rate of presumed thoracolumbar intervertebral disc disease in ambulatory dogs with spinal hyperpathia treated with anti-inflammatory drugs: 78 cases (1997-2000). J Vet Emerg Crit Care. (2007) 17:53-60. doi: 10.1111/j.1476-4431.2006.00195.x

16. Gossard J, Delivet-Mongrain H, Martinez M, Kundu A, Escalona M, Rossignol S. Plastic Changes in lumbar locomotor networks after a partial spinal cord injury in cats. J Neurosci. (2015) 35:9446-55. doi: 10.1523/JNEUROSCI.4502-14.2015

17. Escalona M, Delivet-Mongrain H, Kundu A, Gossard J, Rossignol S. Ladder treadmill: a method to assess locomotion in cats with 
an intact or lesioned spinal cord. J Neurosci. (2017) 37:5429-46. doi: 10.1523/JNEUROSCI.0038-17.2017

18. Martinez $M$, Delivet-Mongrain $H$, Leblond $H$, Rossignol S. Effect of locomotor training in completely spinalized cats previously submitted to a spinal hemisection. J Neurosci. (2012) 32:10961-70. doi: 10.1523/JNEUROSCI.1578-12.2012

19. Hurteau M, Thibaudier Y, Dambreville C, Chraibi A, Desrochers E, Telonio A, et al. Nonlinear modulation of cutaneous reflexes with increasing speed of locomotion in spinal cats. J Neurosci. (2017) 37:3896-912. doi: 10.1523/JNEUROSCI.3042-16.2017

20. Brazg G, Fahey M, Holleran CL, Connolly M, Woodward J, Hennessy PW, et al. Effects of training intensity on locomotor performance in individuals with chronic spinal cord injury: a randomized crossover study. Neurorehabil Neural Repair. (2017) 31:944-54. doi: 10.1177/1545968317731538

21. Engelhardt M, Sobotzik J. Functional neuroanatomy of the spinal cord. In: Weidner N, Rupp R, Tansey K, editors. Neurological Aspects of Spinal Cord Injury. Switzerland: Springer Nature (2017). p. 3-15. doi: 10.1007/978-3-319-46293-6_2

22. Dobkin BH, Apple D, Barbeau H, Basso M, Behrman A, Deforge D, et al. Methods for a randomized trial of weight-supported treadmill training versus conventional training for walking during inpatient rehabilitation after incomplete traumatic spinal cord injury. Neurorehabil Neural Repair. (2003) 17:153-67. doi: 10.1177/0888439003255508

23. Dobkin BH, Duncan PW. Should body weight-supported treadmill training and robotic-assistive steppers for locomotor training trot back to the starting gate? Neurorehabil Neural Repair. (2012) 26:308-17. doi: $10.1177 / 1545968312439687$

24. Dobkin B, Barbeau H, Deforge D, Ditunno J, Elashoff R, Apple D, et al. The evolution of walking-related outcomes over the first 12 weeks of rehabilitation for incomplete traumatic spinal cord injury: the multicenter randomized spinal cord injury locomotor trial. Neurorehabil Neural Repair. (2007) 21:25-35. doi: 10.1177/1545968306295556

25. Labruyère R, van Hedel $H J$. Strenght training versus robot-assisted gait training after incomplete spinal cord injury: a randomized pilot study in patients depending on walking assistance. J Neuroeng Rehabil. (2014) 11:112. doi: $10.1186 / 1743-0003-11-4$

26. Riley PO, Paolini G, Croce UD, Paylo KW, Kerrigan DC. A kinematic and kinetic comparasion of overground and treadmill walking in healthy subjects. Gait Posture. (2007) 26:17-24. doi: 10.1016/j.gaitpost.2006.07.003

27. Lee SJ, Hidler J. Biomechanics of overground vs treadmill walking in healthy individuals. J Appl Physiol. (2008) 104:747-55. doi: 10.1152/japplphysiol.01380.2006

28. Field-Fote EC, Roach KE. Influence of a locomotor training approach on walking speed and distance in people with chronic spinal cord injury: A randomized clinical trial. J Am Phys Ther Assoc. (2010) 91:48-60. doi: 10.2522/ptj.20090359

29. Field-Fote EC, Lindley SD, Sherman AL. Locomotor training approaches for individuals with spinal cord injury: a preliminar report of walking-related outcomes. J Neurol Phys Ther. (2005) 29:127-37. doi: 10.1097/01.NPT.0000282245.31158.09

30. Postans NJ, Hasler JP, Granat MH, Maxwell DJ. Functional electric stimulation to augment partial weight-bearing supported treadmill training for patients with acute incomplete spinal cord injury: a pilot study. Arch Phys Med Rehabil. (2004) 85:604-10. doi: 10.1016/j.apmr.2003.08.083

31. Momeni K, Ramanujam A, Garbarini EL, Forrest GF. Multi-muscle electrical stimulation and stand training: effects on standing. J Spinal Cord Med. (2019) 42:378-86. doi: 10.1080/10790268.2018.1432311

32. Minassian K, Hofstoetter U, Tansey K, Mayr W. Neuromodulation of lower limb motor control in restorative neurology. Clin Neurol Neurosurg. (2012) 114:489-97. doi: 10.1016/j.clineuro.2012.03.013

33. Kwon BK, Okon E, Hillyer J, Mann C, Baptiste D, Weaver LC, et al. A systematic review of non-invasive pharmacologic neuroprotective treatments for acute spinal cord injury. J Neurotrauma. (2011) 28:1545-88. doi: $10.1089 /$ neu.2009.1149

34. Levine JM, Levine GJ, Johnson SI, Kerwin SC, Hettlich BF, Fosgate GT. Evaluation of the success of medical management for presumptive thoracolumbar intervertebral disk herniation in dogs. Vet Surg. (2007) 36:482-91. doi: 10.1111/j.1532-950X.2007.00295.x
35. Amsellem P, Toombs J, Laverty P, Breur G. Loss of deep pain sensation following thoracolumbar intervertebral disk herniation in dogs: Treatment and prognosis. Comp Cont Edu Pract. (2003) 25:266-74.

36. Dewey CW, da Costa RC, Thomas WB. Performing the neurologic examination. In: Dewey CW, da Costa RC, editors. Practical Guide to Canine and Feline Neurology. Oxford: Wiley Blackweel (2016). p. 9-28.

37. Olby NJ, De Risio L, Muñana KR, Wosar MA, Skeen TM, Sharp NJ, et al. Development of a functional scoring system in dogs with acute spinal cord injuries. Am J Vet Res. (2001) 62:1624-8. doi: 10.2460/ajvr.2001.62.1624

38. Levine D, Bockstahler B. Electrical stimulation. In: Millis DL, Levine D, editors. Canine Rehabilitation and Physical Therapy $2^{\text {nd }}$. Philadelphia, PA: Elsevier Saunders (2014). p. 342-58. doi: 10.1016/B978-1-4377-0309-2.00020-X

39. Platt S, Olby NJ. Nursing and rehabilitation of the neurological patient. In: Platt SR, Olby NJ, editors. Canine and Feline Neurology $3^{\text {rd }}$ Ed. British Small Animal Veterinary Association (Gloucester) (2014). p. 394-407.

40. Alluin O, Delivet-Mongrain H, Rossignol S. Inducing hindlimb locomotor recovery in adult rat after complete thoracic spinal cord section using repeated treadmill training with perineal stimulation only. J Neurophysiol. (2015) 114:1931-46. doi: 10.1152/jn.00416.2015

41. Chau C, Barbeau H, Rossignol S. Early locomotor training with clonidine in spinal cats. Am Physiol Soc. (1998) 79:392-409. doi: 10.1152/jn.1998.79.1.392

42. Meyns P, Van de Crommert H, Rijken H, van Kuppevelt D, Duysens J. Locomotor training with body weight support in SCI: EMG improvement is more optimally expressed at a low testing speed. Spinal Cord. (2014) 52:887-93. doi: $10.1038 /$ sc.2014.172

43. Levine D, Millis DL, Flocker J. Aquatic therapy. In: Millis DL, Levine D, editors. Canine Rehabilitation and Physical Therapy, 2nd. Philadelphia, PA: Saunders Elsevier (2014). p. 526-42. doi: 10.1016/B978-1-4377-0309-2.00031-4

44. Gomes-Osman J, Cortes M, Guest J, Pascual-Leone A. A systematic review of experimental strategies aimed at improving motor function after acute and chronic spinal cord injury. J Neurotrauma. (2016) 33:425-38. doi: 10.1089/neu.2014.3812

45. Mushahwar VK, Jacobs PL, Normann RA, Triolo RJ, Kleitman N. New functional electrical stimulation approaches to standing and walking. $J$ Neural Eng. (2007) 4:181-97. doi: 10.1088/1741-2560/4/3/S05

46. Malesevic NM, Popovic LZ, Schwirtlich L, Popovic DB. Distributed low-frequency functional electrical stimulation delays muscle fatigue compared to conventional stimulation. Muscle Nerve. (2010) 42:556-62. doi: $10.1002 /$ mus. 21736

47. Bochkezanian V, Newton RU, Trajano GS, Vieira A, Pulverenti TS, Blazevich AJ. Effect of tendon vibration during wide-pulse neuromuscular electrical stimulation (NMES) on muscle force production in people with spinal cord injury (SCI). BMC Neurol. (2018) 18:17. doi: 10.1186/s12883-018-1020-9

48. Kapadia N, Masani K, Craven BC, Giangregorio LM, Hitzig SL, Richards K, et al. A randomized trial of functional electrical stimulation for walking in incomplete spinal cord injury: effects on walking competency. J Spinal Cord Med. (2014) 37:511-24. doi: 10.1179/2045772314Y.0000000263

49. Barbeau H, Fung J, Leroux A, Ladouceur M. A review of the adaptability and recovery of locomotion after spinal cord injury. Prog Brain Res. (2002) 137:9-25. doi: 10.1016/S0079-6123(02)37004-3

50. Alcobendas-Maestro M, Esclarín-Ruz A, Casado-López RM, MuñozGonzález A, Pérez-Mateos G, González-Valdizán E, et al. Lokomat roboticassisted versus overground training within 3 to 6 months of incomplete spinal cord lesion: randomized controlled trial. Neurorehabil Neural Repair. (2012) 26:1058-63. doi: 10.1177/1545968312448232

51. de Leon RD, Hodgson JA, Roy RR, Edgerton VR. Full weight-bearing hindlimb standing following stand training in the adult spinal cat. $J$ Neurophysiol. (1998) 80:83-91. doi: 10.1152/jn.1998.80.1.83

52. Engesser-Cesar C, Ichiyama RM, Nefas AL, Hill MA, Edgerton VR, Cotman $\mathrm{CW}$, et al. Wheel running following spinal cord injury improves locomotor recovery and stimulates serotonergic fiber growth. Eur J Neurosci. (2007) 25:1931-9. doi: 10.1111/j.1460-9568.2007.05469.x

53. Leech KA, Kinnaird CR, Holleran CL, Kahn J, Hornby TG. Effects of locomotor exercise intensity on gait performance in individuals with incomplete spinal cord injury. Phys Ther. (2016) 96:1919-29. doi: $10.2522 /$ ptj.20150646 
54. Cassilhas RC, Tufik S, Mello MT. Physical exercise, neuroplasticity, spatial learning and memory. Cell Mol Life Sci. (2016) 73:975-83. doi: 10.1007/s00018-015-2102-0

55. Maier IC, Ichiyama RM, Courtine G, Schnell L, Lavrov I, Edgerton VR, et al. Differential effects of anti-Nogo-A antibody treatment and treadmill training in rats with incomplete spinal cord injury. Brain. (2009) 132:1426-40. doi: 10.1093/brain/awp085

56. Shah PK, Garcia-Alias G, Choe J, Gad P, Gerasimenko Y, Tillakaratne N, et al. Use of quadrupedal step training to re-engage spinal interneuronal networks and improve locomotor function after spinal cord injury. Brain. (2013) 136:3362-77. doi: 10.1093/brain/awt265

57. Campbell MT, Huntingford JL. Nursing care and rehabilitation therapy for patients with neurologic disease. In: Dewey CW, da Costa RC, editors. Practical Guide to Canine and Feline Neurology. Oxford: Wiley Blackweel (2016). p. 559-83.

58. Martins Â, Ferreira A. Neuroreabilitação funcional em lesões medulares. In: Lopes RS, Diniz R, editors. Fisiatria em pequenos animais 1st Ed. São Paulo: Editora Inteligente (2018). p. 287-98.

59. Ingram EA, Kale DC, Balfour RJ. Hemilaminectomy for thoracolumbar Hansen type I Intervertebral disck disease in ambulatory dogs with or without neurologic deficits: 39 cases (2008-2010). Vet Surg. (2013) 42:92431. doi: 10.1111/j.1532-950X.2013.12061.X

60. Castel A, Olby NJ, Mariani CL, Muñana KR, Early PJ. Clinical characteristics of dogs with progressive myelomalacia following acute intervertebral disc extrusion. J Vet Intern Med. (2017) 31:1782-9. doi: 10.1111/jvim.14829

61. Fenn J, Laber E, Williams K, Rousse CA, Early PJ, Mariani CL, et al. Associations between anesthetic variables and functional outcome in dogs with thoracolumbar intervertebral disk extrusion undergoing decompressive hemilaminectomy. J Vet Intern Med. (2017) 31:814-24. doi: $10.1111 /$ jvim. 14677

62. Lewis MJ, Cohen EB, Olby NJ. Magnetic resonance imaging features of dogs with incomplete recovery after acute, severe spinal cord injury. Spinal Cord. (2018) 56:133-41. doi: 10.1038/s41393-017-0004-8

63. Olby NJ, Lim J, Wagner N, Zidan N, Early PJ, Mariani CL, et al. Time course and prognostic value of serum GFAP, pNFH, and S100p concentrations in dogs with complete spinal cord injury because of intervertebral disc extrusion. J Vet Intern Med. (2019) 33:726-34. doi: 10.1111/jvim.15439

64. Aikawa T, Shibata M, Asano M, Hara Y, Tagawa M, Orima H. A comparison of thoracolumbar intervertebral disc extrusion in french bulldogs and dachshunds and association with congenital vertebral anomalies. Vet Surg. (2014) 43:301-7. doi: 10.1111/j.1532-950X.2014.12102.x

65. Bennaim M, Porato M, Jarleton A, Hamon M, Carroll JD, Gommeren $\mathrm{K}$, et al. Preliminary evaluation of the effects of photobiomodulation therapy and physical rehabilitation on early postoperative recovery of dogs undergoing hemilaminectomy for treatment of thoracolumbar intervertebral disk disease. AJVR. (2017) 78:195. doi: 10.2460/ajvr.78.2.195

66. Hansen HJ. A pathologic-anatomical interpretation of disc degeneration in dogs. Acta Orthop Scand Suppl. (1951) 20:280-93. doi: $10.3109 / 17453675108991175$

67. Hansen HJ. Comparative views of the pathology of disk degeneration in animals. Lab Invest. (1959) 8:1242-65.

68. Kinzel S, Wolff M, Buecker A, Krombach GA, Stopinski T, Afify M, et al. Partial percutaneous discectomy for treatment of thoracolumbar disc protrusion: retrospective study of 331 dogs. J Small Anim Practice. (2005) 46:479-84. doi: 10.1111/j.1748-5827.2005.tb00276.x

69. Bergknut N, Auriemma E, Wijsman S, Voorhout G, Hagman R, Lagerstedt A, et al. Evaluation of intervertebral disk degeneration in condrodystrophic and nonchondrodystrophic dogs by use of Pfirrmann grading of images obtained with low-field magnetic resonance imaging. Am J Vet Res. (2011) 72:893-8. doi: 10.2460/ajvr.72.7.893

70. Lainiten OM, Puerto DA. Surgical decompression in dogs with thoracolumbar intervertebral disc disease and loss of deep pain perception: A retrospective study of 46 cases. Acta Vet Scand. (2005) 46:79-85. doi: 10.1186/1751-0147-46-79

71. Ruddle TL, Allen DA, Schertel ER, Barnhart MD, Wilson ER, Lineberger JA, et al. Outcome and prognostic factors in non-ambulatory Hansen type I intervertebral disk extrusions: 308 cases. Vet Comp Orthop Traumatol. (2006) 19:29-34. doi: 10.1055/s-0038-1632970
72. Zidan N, Sims C, Fenn J, Williams K, Griffith E, Early PJ, et al. A randomized, blinded, prospective clinical trial of postoperative rehabilitation in dogs after surgical decompression of acute thoracolumbar intervertebral disc herniation. J Vet Intern Med. (2018) 32:1133-44. doi: 10.1111/jvim.15086

73. Ball MU, McGuire JA, Swaim SF, Hoerlein BF. Patterns of occurrence of disk disease among registered dachshunds. J Am Vet Med Assoc. (1982) 180:51922.

74. Thomas WB, Fingeroth JM, Hagman R. What do we know about the incidence of disc disease in chondrodystrophoid dogs? In: Fingeroth JM, Thomas WB, editors. Advances in Intervertebral Disc Disease in Dogs and Cats. Iowa: American College of Veterinary Surgeons Foundation \& Wiley Blackwell (2015). doi: 10.1002/9781118940372

75. Côté MP, Ménard A, Gossard JP. Spinal cats on the treadmill: changes in load pathways. J Neurosci. (2003) 23:2789-96. doi: 10.1523/JNEUROSCI.23-07-02789.2003

76. Côté MP, Gossard JP. Step training-dependent plasticity in spinal cutaneous pathways. J Neurosci. (2004) 24:11317-27. doi: 10.1523/JNEUROSCI.1486-04.2004

77. Lavrov I, Gerasimenko YP, Ichiyama RM, Courtine G, Zhong H, Roy RR, et al. Plasticity of spinal cord reflexes after a complete transection in adult rats: relationship to stepping ability. J Neurophysiol. (2006) 96:1699-710. doi: 10.1152/jn.00325.2006

78. Van Den Brand R, Heutschi J, Barraud Q, DiGiovanna J, Bartholdi $\mathrm{K}$, Huerlimann $\mathrm{M}$, et al. Restoring voluntary control of locomotion after paralyzing spinal cord injury. Science. (2012) 336:1182-5. doi: $10.1126 /$ science. 1217416

79. Musienko PE, Deliagina TG, Gerasimenko YP, Orlovsky GN, Zelenin PV. Limb and trunk mechanisms for balance control during locomotion in quadrupeds. J Neurosci. (2014) 34:5704-16. doi: 10.1523/JNEUROSCI.4663-13.2014

80. Rossignol S, Martinez M, Escalona M, Kundu A, Delivet-Mongrain H, Alluin $\mathrm{O}$, et al. The "beneficial" effects of locomotor training after various types of spinal lesions in cats and rats. In: Dancause N, Nadeau S, Rossignol S, editors. Sensorimotor Rehabilitation: At the Crossroad of Basic and Clinical Sciences. Oxford: Elsevier (2015). p. 173-98. doi: 10.1016/bs.pbr.2014.12.009

81. Harkema SJ, Behrman AL, Barbeau H. Locomotor Training: Principles and Practice. New York, NY: Oxford UP (2011).

82. Smith AC, Mummidisetty CK, Rymer WZ, Knikou M. Locomotor training alters the behavior of flexor reflexes during walking in human spinal cord injury. J Neurophysiol. (2014) 112:2164-75. doi: 10.1152/jn.003 08.2014

83. Leech KA, Hyosub EK, Hornby G. Strategies to augment volitional and reflex function may improve locomotor capacity following incomplete spinal cord injury. J Neurophysiol. (2017) 119:894-903. doi: 10.1152/jn.00051.2017

84. Lang C, Bradley PM, Jacobi A, Kerschensteiner M, Bareyre FM. STAT3 promotes corticospinal remodelling and functional recovery after spinal cord injury. EMBO Rep. (2013) 14:931-7. doi: 10.1038/embor.2013.117

85. Martinez M, Brezun JM, Zennou-Azogui Y, Baril N, Xerri C. Sensorimotor training promotes functional recovery and somatosensory cortical map reactivation following cervical spinal cord injury. Eur J Neurosci. (2009) 30:2356-67. doi: 10.1111/j.1460-9568.2009.07019.x

86. Bregman BS. Regeneration in the spinal cord. Curr Opin neurobiol. (1998) 8:800-7. doi: 10.1016/S0959-4388(98)80124-4

87. Thomas SL, Gorassini MA. Increases in corticospinal tract function by treadmill training after incomplete spinal cord injury. J Neurophysiol. (2005) 94:2844-55. doi: 10.1152/jn.00532.2005

88. Field-Fote E, Tepavac D. Combined use of body weight support, functional electric stimulation, and treadmill training to improve walking ability in individuals with chronic incomplete spinal cord injury. Arch Phys Med Rehabil. (2001) 82:818-24. doi: 10.1053/apmr.2001. 23752

89. Ibitoye MO, Hamzaid NA, Hasnan N, Wahab A, Davis GM. Strategies for rapid muscle fatigue reduction during FES exercise in individuals with spinal cord injury: A systematic review. PLoS ONE. (2016) 11:149024. doi: 10.1371/journal.pone.0149024

90. Ragnarsson KT. Functional electrical stimulation after spinal cord injury: current use, therapeutic effects and future directions. Spinal Cord. (2008) 46:255-74. doi: 10.1038/sj.sc.3102091 
91. Côté MP, Murray M, Lemay MA. Rehabilitation strategies after spinal cord injury: Inquiry into the mechanisms of success and failure. J Neurotrauma. (2017) 34:1841-57. doi: 10.1089/neu.2016.4577

92. Pette D, Vrbová G. The contribution of neuromuscular stimulation in elucidating muscle plasticity revisited. Eur J Transl Myol. (2017) 27:33-9. doi: 10.4081 /ejtm.2017.6368

93. Sivaramakrishnan A, Solomon JM, Manikandan N. Comparasion of transcutaneous electrical nerve stimulation (TENS) and functional electrical stimulation (FES) for spasticity in spinal cord injury - a pilot randomized cross-over trial. J Spinal Cord Med. (2018) 41:397-406. doi: 10.1080/10790268.2017.1390930

94. Doucet BM, Lam A, Griffin L. Neuromuscular electrical stimulation for skeletal muscle function. Yale J Biol Med. (2012) 85:201-15. doi: 10.1016/j.jelekin.2011.12.005

95. Glinsky J, Harvey L, Van Es P. Efficacy of electrical stimulation to increase muscle strength in people with neurological conditions: a systematic review. Physiother Res Int. (2007) 12:175-94. doi: 10.1002/ pri.375

96. Hubli M, Dietz V. The physiological basis of neurorehabilitation - locomotor training after spinal cord injury. J Neuroeng Rehabil. (2013) 10:1-8. doi: 10.1186/1743-0003-10-5

97. Honeycutt CF, Gottschall JS, Nichils TR. Electromyographic responses from the hindlimb muscles of the decerebrate cat to horizontal support surface perturbations. J Neurophysiol. (2009) 101:2751-61. doi: 10.1152/jn.91040.2008

98. Musselman KE, Fouad K, Misiaszek JE, Yang JF. Training of walking skills overground and on the treadmill: case series on individuals with incomplete spinal cord injury. J Am Phys Ther Ass. (2009) 89:601-11. doi: $10.2522 /$ ptj.20080257

99. Zewdie ET, Roy FD, Yang JF, Gorassini MA. Facilitation of descending excitatotory and spinal inhibitory networks from training of endurance and precision walking in participants with incomplete spinal cord injury. Prog Brain Res. (2015) 218:127-55. doi: 10.1016/bs.pbr.2014.12.005

100. Wessels M, Lucas C, Eriks I, Groot S. Body weight-supported gait training for restorarion of walking in people with an incomplete spinal cord injury: a systematic review. J Rehabil Med. (2010) 42:513-9. doi: 10.2340/16501977-0525

101. Daly JJ, Zimbelman J, Roenigk KL, McCabe JP, Rogers JM, Butler K, et al. Recovery of coordinated gait: randomized controlled stroke trial of functional electrical stimulation (FES) versus no FES, with weight-supported treadmill and Over-Ground training. Neurorehabil Neural Repair. (2011) 25:588-96. doi: 10.1177/1545968311400092

Conflict of Interest: The authors declare that the research was conducted in the absence of any commercial or financial relationships that could be construed as a potential conflict of interest.

Copyright (c) 2021 Martins, Gouveia, Cardoso, Viegas, Gamboa and Ferreira. This is an open-access article distributed under the terms of the Creative Commons Attribution License (CC BY). The use, distribution or reproduction in other forums is permitted, provided the original author(s) and the copyright owner(s) are credited and that the original publication in this journal is cited, in accordance with accepted academic practice. No use, distribution or reproduction is permitted which does not comply with these terms. 